\title{
Predictive Risk Factors for Refracture after Percutaneous Vertebroplasty
}

\author{
Sang-Kuk Kang, M.D., Ph.D., Chan Woo Lee, M.D., Noh Kyoung Park, M.D., Tae-Wook Kang, M.D., \\ Jeong-Wook Lim, M.D. ${ }^{1}$, Ki Yong Cha, M.D. ${ }^{1}$ Jung Hwan Kim, M.D., Ph.D. ${ }^{2}$
}

Department of Rehabilitation Medicine, ${ }^{1}$ Neurosurgery, Sun General Hospital, Daejeon 301-725, ${ }^{2}$ Kangwon National University School of Medicine and Hospital, Regional Cardiocerebrovascular Center, Chuncheon 200-722, Korea

Objective To identify risk factors for developing a vertebral refracture after percutaneous vertebroplasty. Method A retrospective analysis of 60 patients who had undergone percutaneous vertebroplasty between January 2008 and April 2010 was conducted. All patients were observed for a 1 year follow-up period, and fracture was defined when it was both clinically reported and radiographically confirmed. Twenty-seven patients with a refractured vertebra and 33 patients without a refracture were included. Of the 60 patients, 20 presented with a refracture from a cemented vertebra, whereas the remaining 40 patients did not. Clinical, imaging and procedurerelated factors for each group were analyzed by the Fisher's exact, chi-square, and the Mann-Whitney $U$-tests.

Results Local kyphotic angle and sagittal index were significant as a result of researching various risk factors related to vertebral refracture $(\mathrm{p}<0.001, \mathrm{p}<0.001$, respectively) and refracture from a cemented vertebra itself ( $\mathrm{p}=0.004, \mathrm{p}<0.001$, respectively). Other factors were not significant.

Conclusion Patients who had a high preoperative local kyphotic angle and a high sagittal index required a close follow-up and attention.

Key Words Risk factor, Refracture, Percutaneous vertebroplasty, Local kyphotic angle, Sagittal index

\section{INTRODUCTION}

The most common cause of a vertebral compression

Received June 15, 2011; Accepted October 10, 2011

Corresponding author: Chan Woo Lee

Department Rehabilitation Medicine, Sun General Hospital, 10-7, Mokdong, Jung-gu, Daejeon 301-725, Korea

Tel : +82-42-220-8468, Fax : +82-303-3130-8468, E-mail: sky20525@naver. com

(c) This is an open-access article distributed under the terms of the Creative Commons Attribution Non-Commercial License (http:// creativecommons.org/licenses/by-nc/3.0) which permits unrestricted noncommercial use, distribution, and reproduction in any medium, provided the original work is properly cited.

Copyright $\odot 2011$ by Korean Academy of Rehabilitation Medicine fracture is osteoporosis, which reduces vertebral body bone mass, changes fine bone structure, and ultimately makes it more vulnerable to a compression fracture even by a small external force. ${ }^{1}$ Classic conservative treatments for a vertebral compression fracture include bed rest, orthosis use, and drug treatment for osteoporosis and pain. However, despite proper conservative treatment, some patients continue to have severe pain and neurological symptoms that persist, and the vertebral compression and kyphotic deformity progresses. As these eventually cause problems in life and lower the quality of life, a more positive treatment is needed. Percutaneous vertebroplasty has recently been used and has provided 
good results, instead of operative treatments, such as anterior and posterior spinal fusion, which can cause great risk due to general anesthesia., ${ }^{2,3}$

Percutaneous vertebroplasty is widely used, as it is very effective for reducing pain caused by an osteoporotic vertebral compression fracture and is easy and safe to use. ${ }^{4}$ It also restores the height of a vertebral body with a fracture; thus, reducing kyphotic deformity of the vertebral column and complications in the respiratory and gastrointestinal systems. ${ }^{4}$ Refracture of a vertebra can often occur after percutaneous vertebroplasty, and the rate of refracture of cemented vertebra and other vertebra is $12-52 \%{ }^{5-8}$ The representative risk factor associated with refracture after percutaneous vertebroplasty is osteoporosis; the lower the bone mineral density (BMD) is, the more frequently a refracture develops with greater severity, consequently increasing the need for invasive treatments, such as posterior spinal fusion. ${ }^{9}$ Other factors associated with refracture include percutaneous vertebroplasty and the volume and distribution pattern of cement injected into the fractured vertebra. ${ }^{10-13}$ While some suggest that refractures developing in patients who had undergone percutaneous vertebroplasty should be regarded as a natural progression of osteoporosis, ${ }^{3}$ the resulting severe pain, progression of kyphotic deformity, and risk of operative treatment are significant problems for aged patients. However, current treatments mostly focus on the fractured vertebra alone, sometimes discontinuing outpatient follow-up observation postoperatively and, consequently, exposing many patients to the possible risk of developing a refracture.

In this context, we retrospectively analyzed risk factors in patients who had suffered from a refracture after undergoing percutaneous vertebroplasty for a compression fracture with the objective of identifying predictive factors for refracture.

\section{MATERIALS AND METHODS}

\section{Subjects}

Of those patients who were observed for a followup period of 1 year after undergoing percutaneous vertebroplasty for a compression fracture on only one spinal segment between January 1, 2008 and April 30, 2010 at the Spine Center in this hospital, 60 patients who had used thoraco-lumbo-sacral orthosis after undergoing percutaneous vertebroplasty for more than 2 weeks and who took medication for osteoporosis (resedronate 35 $\mathrm{mg}$ /week) as prescribed, and for whom proper comparable radiological images were kept, and who had no history of spinal surgery, malignant tumor, or steroid use were tested for vertebral refractures. Percutaneous vertebroplasty was conducted by two neurosurgeons with sufficient clinical experience and the skills designed by Jensen et al. ${ }^{14}$ using Simplex P polymethylmethacrylate cement (Stryker, Kalamazoo, USA), which is a mix of barium sulfate powder and tobramycin. Refracture of a vertebra was defined as reoccurrence of a symptom suggesting a vertebral fracture in a patient whose symptoms associated with the initial vertebral fracture had improved, who felt tenderness in the vertebral region on a medical examination, and for whom a feature of acute vertebral fracture was identified by nuclear medicine using nuclear isotopes ( ${ }^{99} \mathrm{mTC}$ MDP) and spinal magnetic resonance imaging (MRI). Of the 60 patients, 27 patients had vertebral refractures: 18 with a refracture of a cemented vertebra, seven with a subsequent fracture of the adjacent vertebra, and two with a refracture of both the cemented vertebra and a subsequent fracture.

For comparative analysis of various risk factors contributing to the development of a vertebral refracture after percutaneous vertebroplasty, the 60 patients were classified into the following categories according to the refracture level. First, they were categorized into a group of 27 patients with a vertebral refracture and 33 without such a fracture. Second, they were divided into a group of 20 with a refracture of the cemented vertebra and that of 40 without such a refracture.

\section{Methodology}

Age, gender, height, weight, body mass index (BMI), lumbar BMD, visual analogue scale before percutaneous vertebroplasty, and gas contained in the vertebral body were examined. The vertebral regions for percutaneous vertebroplasty were divided into three groups: thoracic vertebra (T4-T9), thoraco-lumbar vertebra (T10-L2), and the lumbar vertebra (L3-L5). The distribution patterns of the cement injected into the vertebra were divided into cleft and trabecular types (Fig. 1). ${ }^{15}$ When cement went over the lamina terminalis of the vertebral body concerned and when it was discovered within an adjacent disk, both were regarded as cement leakage, and 

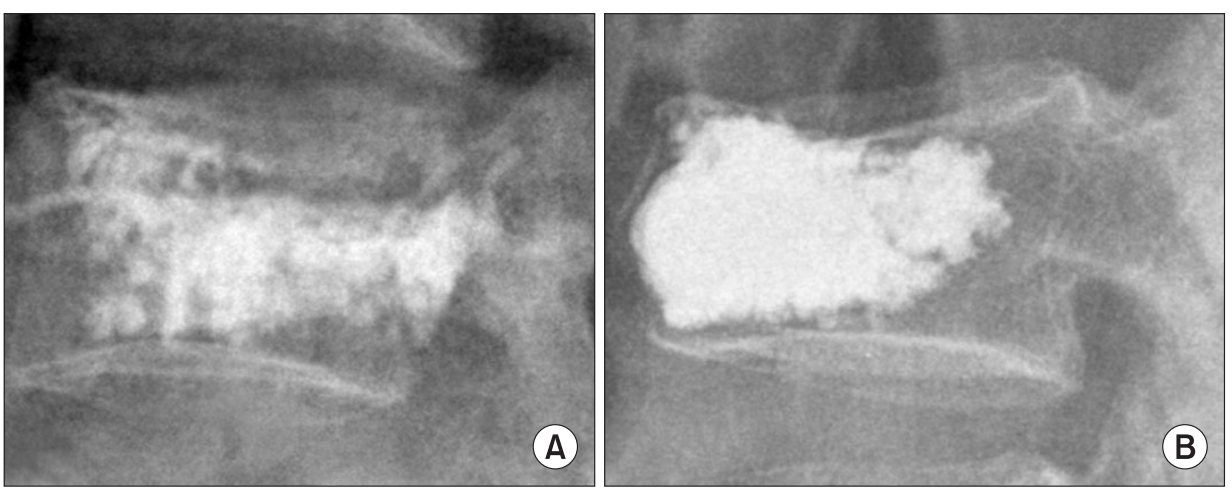

Fig. 1. Cement distribution patterns (A) T type: Sponge-like cement filling a vertebral body. (B) C type: Compact and solid cement filling a vertebral body.

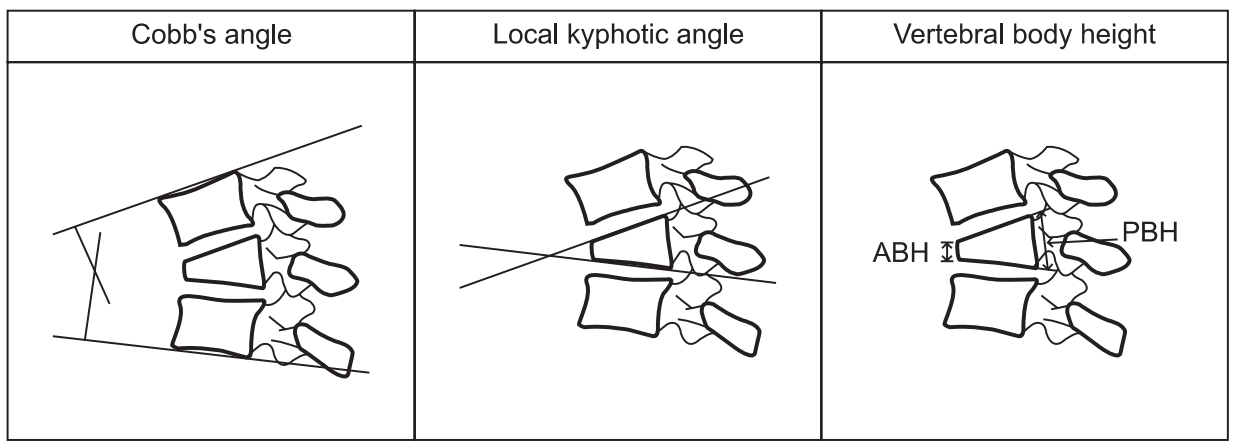

Fig. 2. Measurement of kyphotic deformity. ABH: anterior body height, PBH: posterior body height.

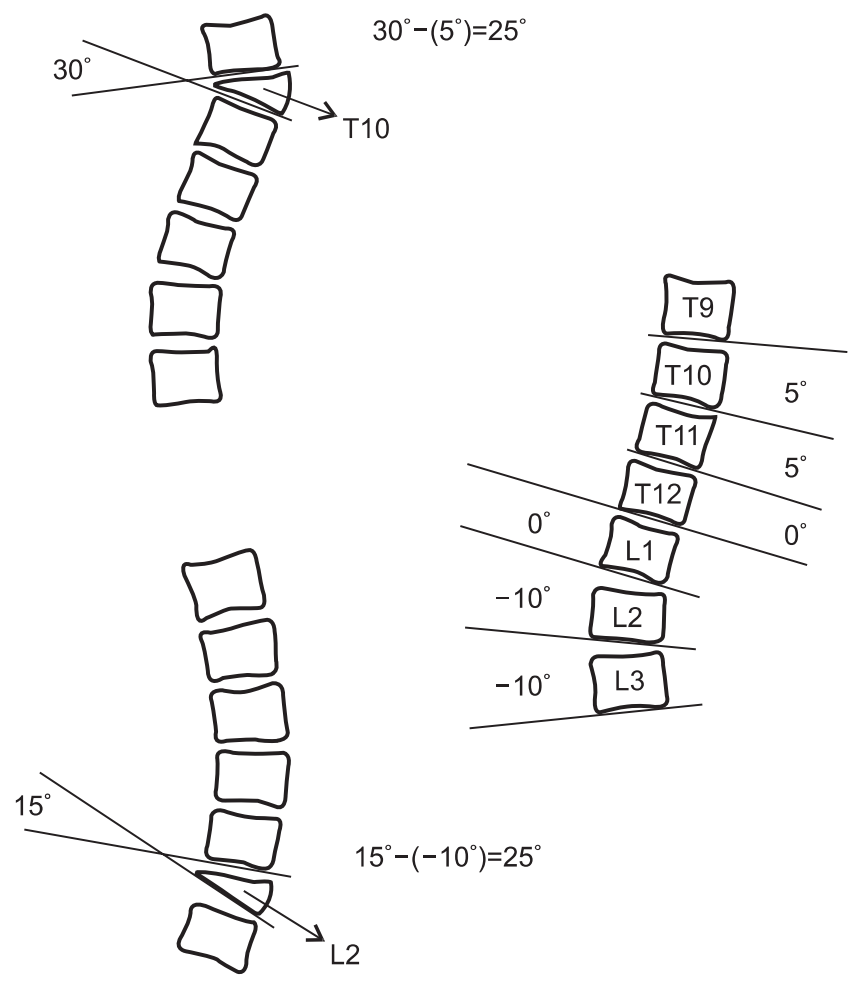

Kyphotic deformity-normal contour=Sagittal index

Fig. 3. Measurement of the sagittal index. cement injection volume was examined. Cobb's angle, the local kyphotic angle, height of the vertebral body, and the sagittal index were measured before vertebroplasty to assess the intensity of kyphotic deformity of the vertebral column following the compression fracture (Fig. $2,3)$. The sagittal index suggested by Farcy et al. ${ }^{16}$ was obtained by subtracting the normal sagittal angle from the vertebral kyphotic angle affected by fracture, and the normal sagittal angle was estimated by regarding it as $5^{\circ}$ kyphosis $(+5)$ per segment in the thoracic vertebra, as neutral (0) in the 12th thoracic and 1st lumbar vertebra, and as $10^{\circ}$ lordosis $(-10)$ in the lumbar vertebra. A single doctor investigated and recorded the radiological data.

\section{Statistics}

Data were analyzed using the SPSS 12.0 statistical program (SPSS Inc., Chicago, USA). Fisher's exact test was used to compare the groups in terms of gender, cement leakage, and the vertebral region for percutaneous vertebroplasty. The chi-square test was used to compare the groups in terms of cement leakage and gas contained in the vertebral body. The Mann-Whitney U-test was performed to compare the groups in terms of age, height, BMI, lumbar BMD, cement injection volume, visual ana- 
logue scale before percutaneous vertebroplasty, Cobb's angle, local kyphosis angle, height of the vertebral body, and the sagittal index. A p-value $<0.05$ was considered significant.

\section{RESULTS}

The average age of the 60 patients was 70 years, and there were 10 men and 50 women. The vertebra, except the fractured region, had an average BMD of $-2.4 \mathrm{~g} / \mathrm{cm}^{2}$, and the patients had an average BMI of $24.3 \mathrm{~kg} / \mathrm{m}^{2}$. Fortytwo patients had undergone percutaneous vertebroplasty at the thoraco-lumbar vertebra (T10-L2), $6.0 \mathrm{ml}$ of cement on average was injected for percutaneous vertebroplasty, and a vertebral refracture developed 225.5 days after percutaneous vertebroplasty on average.

\section{Classification by development of a refractured vertebra}

The local kyphotic angles in patients with a vertebral refracture and the 33 without a refracture were $15.6 \pm 6.7^{\circ}$ and $9.4 \pm 6.1^{\circ}$, and the sagittal index was $12.7 \pm 6.5^{\circ}$ and $6.7 \pm 7.2^{\circ}$, respectively. Significant differences in the local kyphotic angle and the sagittal index were observed between the groups formed by the development of a

Table 1. The Relationship between Risk Factors and Each Group

\begin{tabular}{|c|c|c|c|c|c|c|}
\hline Risk factor & $\begin{array}{l}\text { Without Re-Fx. } \\
\text { in thoracolumbar } \\
\text { vertebra }(n=33)\end{array}$ & $\begin{array}{c}\text { With Re-Fx. } \\
\text { in thoracolumbar } \\
\text { vertebra }(n=27)\end{array}$ & p-value & $\begin{array}{l}\text { Without Re-Fx. } \\
\text { in cemented } \\
\text { vertebra } \\
(n=40)\end{array}$ & $\begin{array}{c}\text { With Re-Fx. } \\
\text { in cemented } \\
\text { vertebra }(n=20)\end{array}$ & p-value \\
\hline Cobb angle $\left({ }^{\circ}\right)$ & $\begin{array}{c}14.2 \pm 12.8 \\
(-28.6-43.3)\end{array}$ & $\begin{array}{c}18.8 \pm 15.3 \\
(-24.3-48.0)\end{array}$ & 0.089 & $\begin{array}{c}15.4 \pm 14.0 \\
(-28.6-48.0)\end{array}$ & $\begin{array}{c}18.0 \pm 14.3 \\
(-24.3-34.5)\end{array}$ & 0.168 \\
\hline Local kyphotic angle $\left({ }^{\circ}\right)$ & $\begin{array}{c}9.4 \pm 6.1 \\
(-5.7-25.0)\end{array}$ & $\begin{array}{c}15.6 \pm 6.7 \\
(0.4-28.7)\end{array}$ & $0.000^{*}$ & $\begin{array}{l}10.4 \pm 6.4 \\
(-5.7-25.0)\end{array}$ & $\begin{array}{c}15.8 \pm 7.1 \\
(0.4-28.7)\end{array}$ & 0.004 \\
\hline Sagittal index & $\begin{array}{c}6.7 \pm 7.2 \\
(-4.0-28.8)\end{array}$ & $\begin{array}{c}12.7 \pm 6.5 \\
(-2.7-24.5)\end{array}$ & $0.000^{*}$ & $\begin{array}{c}7.1 \pm 7.1 \\
(-4.0-28.8)\end{array}$ & $\begin{array}{c}14.0 \pm 6.2 \\
(-1.5-24.5)\end{array}$ & $0.000^{*}$ \\
\hline $\mathrm{ABH}(\mathrm{mm})$ & $\begin{array}{l}18.3 \pm 6.1 \\
(4.2-30.5)\end{array}$ & $\begin{array}{c}16.5 \pm 6.9 \\
(4.0-31.4)\end{array}$ & 0.306 & $\begin{array}{l}17.5 \pm 6.2 \\
(4.0-30.5)\end{array}$ & $\begin{array}{c}17.5 \pm 7.1 \\
(5.5-31.4)\end{array}$ & 0.985 \\
\hline $\mathrm{PBH}(\mathrm{mm})$ & $\begin{array}{c}26.7 \pm 5.7 \\
(11.8-37.3)\end{array}$ & $\begin{array}{c}25.6 \pm 5.3 \\
(16.0-39.0)\end{array}$ & 0.453 & $\begin{array}{c}25.7 \pm 5.7 \\
(11.8-37.3)\end{array}$ & $\begin{array}{c}27.1 \pm 5.0 \\
(16.0-39.0)\end{array}$ & 0.349 \\
\hline Height $(\mathrm{cm})$ & $\begin{array}{c}154.4 \pm 8.2 \\
(141.0-175.0)\end{array}$ & $\begin{array}{c}151.2 \pm 7.1 \\
(138.0-171.4)\end{array}$ & 0.117 & $\begin{array}{c}153.3 \pm 7.9 \\
(141.0-175.0)\end{array}$ & $\begin{array}{c}152.3 \pm 7.7 \\
(138.0-171.4)\end{array}$ & 0.623 \\
\hline Weight (kg) & $\begin{array}{c}57.2 \pm 9.4 \\
(37.2-83.0)\end{array}$ & $\begin{array}{r}57.1 \pm 12.5 \\
(33.8-92.0)\end{array}$ & 0.528 & $\begin{array}{c}57.4 \pm 8.9 \\
(37.2-83.0)\end{array}$ & $\begin{array}{r}56.7 \pm 14.2 \\
(33.8-92.0)\end{array}$ & 0.236 \\
\hline $\mathrm{BMI}\left(\mathrm{kg} / \mathrm{m}^{2}\right)$ & $\begin{array}{c}22.8 \pm 1.3 \\
(17.2-32.5)\end{array}$ & $\begin{array}{c}22.6 \pm 1.2 \\
(17.7-33.0)\end{array}$ & 0.673 & $\begin{array}{c}22.9 \pm 1.3 \\
(17.7-32.5)\end{array}$ & $\begin{array}{c}22.5 \pm 1.2 \\
(17.2-33.0)\end{array}$ & 0.630 \\
\hline Spine BMD $\left(\mathrm{g} / \mathrm{cm}^{2}\right)$ & $\begin{array}{l}-2.3 \pm 1.5 \\
(-5.0-1.9)\end{array}$ & $\begin{array}{c}-2.7 \pm 1.0 \\
(-3.9--0.1)\end{array}$ & 0.483 & $\begin{array}{l}-2.4 \pm 1.4 \\
(-5.0-1.9)\end{array}$ & $\begin{array}{c}-2.6 \pm 1.1 \\
(-3.9-0.1)\end{array}$ & 0.807 \\
\hline Injection vol. (ml) & $\begin{array}{c}6.4 \pm 1.6 \\
(3.0-10.0)\end{array}$ & $\begin{array}{c}6.1 \pm 2.6 \\
(0.5-14.0)\end{array}$ & 0.138 & $\begin{array}{c}6.5 \pm 1.6 \\
(3.0-10.0)\end{array}$ & $\begin{array}{c}6.4 \pm 2.8 \\
(0.5-14.0)\end{array}$ & 0.873 \\
\hline VAS & $\begin{array}{c}8.2 \pm 1.3 \\
(6.0-10.0)\end{array}$ & $\begin{array}{c}7.9 \pm 1.7 \\
(4.0-10.0)\end{array}$ & 0.549 & $\begin{array}{c}8.3 \pm 1.3 \\
(6.0-10.0)\end{array}$ & $\begin{array}{c}7.7 \pm 1.8 \\
(4.0-10.0)\end{array}$ & 0.236 \\
\hline Age (years) & $\begin{array}{c}69.4 \pm 6.4 \\
(55.0-84.0)\end{array}$ & $\begin{array}{c}70.3 \pm 6.8 \\
(53.0-81.0)\end{array}$ & 0.603 & $\begin{array}{c}69.6 \pm 6.2 \\
(55.0-84.0)\end{array}$ & $\begin{array}{c}70.1 \pm 7.3 \\
(53.0-81.0)\end{array}$ & 0.783 \\
\hline
\end{tabular}

Data are presented as mean \pm SD

Re-Fx.: Refracture, ABH: Anterior body height, PBH: Posterior body height, BMI: Body mass index, BMD: Bone mineral density, VAS: Visual analogue scale

Statistical significance was defined as $\mathrm{p}<0.05,{ }^{*} \mathrm{p}<0.001$ by Mann-Whitney $U$-test 
vertebral refracture $(\mathrm{p}<0.001, \mathrm{p}<0.001)($ Table 1$)$.

\section{Classification by refracture of a cemented vertebra}

The local kyphotic angles between the 20 patients with a refractured cemented vertebra and the 40 without a refracture were $15.8 \pm 7.1^{\circ}$ and $10.4 \pm 6.4^{\circ}$, and the sagittal index was $14.0 \pm 6.2^{\circ}$ and $7.1 \pm 7.1^{\circ}$, respectively. Significant differences in the local kyphotic angle and the sagittal index were observed between the groups formed by the refracture of cemented vertebra $(\mathrm{p}<0.004, \mathrm{p}<0.001)$ (Table 1).

No significant differences in other risk factors were observed between the groups (Table 1, 2).

\section{DISCUSSION}

A vertebral compression fracture is a common clinical condition with a prevalence of $81-153$ per 100,000 persons ${ }^{17}$. These types of fractures can be treated conservatively, with an operation, or by percutaneous vertebroplasty. No research has directly compared the rate of refracture after the most popular conservative treatment compared to that after operative treatment for severe spinal deformities or neurological symptoms. But, Sohn et al. ${ }^{1}$ reported that the rate of refracture after popular conservative treatment was $25-52.4 \%$ based on radiological fracture diagnosis criteria. Choi et al., who conducted research among 19 patients undergoing pedicle screw fixation through a posterior approach

Table 2. The Relationship between Risk Factors and Each Group

\begin{tabular}{|c|c|c|c|c|c|}
\hline \multirow{2}{*}{$\begin{array}{l}\text { Risk factor } \\
\text { Sex* }\end{array}$} & \multirow[t]{2}{*}{ Group } & \multicolumn{3}{|c|}{ Type } & \multirow[t]{2}{*}{ p-value } \\
\hline & & $\mathrm{F}$ & & M & \\
\hline & Without Re-Fx. in thoracolumbar vertebra $(n=33)$ & 27 & & 6 & 1.000 \\
\hline & With Re-Fx. in thoracolumbar vertebra $(\mathrm{n}=27)$ & 23 & & 4 & \\
\hline & Without Re-Fx. in cemented vertebra $(n=40)$ & 34 & & 6 & 0.718 \\
\hline & With Re-Fx. in cemented vertebra $(n=20)$ & 16 & & 4 & \\
\hline \multirow[t]{5}{*}{ Distribution pattern* } & & T type & & C type & \\
\hline & Without Re-Fx. in thoracolumbar vertebra $(n=33)$ & 25 & & 8 & 0.315 \\
\hline & With Re-Fx. in thoracolumbar vertebra $(\mathrm{n}=27)$ & 24 & & 3 & \\
\hline & Without Re-Fx. in cemented vertebra $(n=40)$ & 30 & & 10 & 0.081 \\
\hline & With Re-Fx. in cemented vertebra $(n=20)$ & 19 & & 1 & \\
\hline \multirow[t]{5}{*}{ Cement leakage $^{\dagger}$} & & None & & tradiscal & \\
\hline & Without Re-Fx. in thoracolumbar vertebra $(n=33)$ & 25 & & 8 & 0.639 \\
\hline & With Re-Fx. in thoracolumbar vertebra $(\mathrm{n}=27)$ & 19 & & 8 & \\
\hline & Without Re-Fx. in cemented vertebra $(n=40)$ & 30 & & 10 & 0.680 \\
\hline & With Re-Fx. in cemented vertebra $(n=20)$ & 14 & & 6 & \\
\hline \multirow[t]{5}{*}{ Gas contain $^{\dagger}$} & & No & & Yes & \\
\hline & Without Re-Fx. in thoracolumbar vertebra $(n=33)$ & 26 & & 7 & 0.291 \\
\hline & With Re-Fx. in thoracolumbar vertebra $(n=27)$ & 18 & & 9 & \\
\hline & Without Re-Fx. in cemented vertebra $(n=40)$ & 31 & & 9 & 0.302 \\
\hline & With Re-Fx. in cemented vertebra $(n=20)$ & 13 & & 7 & \\
\hline \multirow[t]{5}{*}{ Fx. level* } & & T10-L2 & L2-L5 & $\mathrm{T} 4-\mathrm{T} 10$ & \\
\hline & Without Re-Fx. in thoracolumbar vertebra $(n=33)$ & 24 & 8 & 1 & 0.329 \\
\hline & With Re-Fx. in thoracolumbar vertebra $(\mathrm{n}=27)$ & 18 & 5 & 4 & \\
\hline & Without Re-Fx. in cemented vertebra $(n=40)$ & 27 & 10 & 3 & 0.666 \\
\hline & With Re-Fx. in cemented vertebra $(n=20)$ & 15 & 3 & 2 & \\
\hline
\end{tabular}

Statistical significance was defined as $\mathrm{p}<0.05$

Re-Fx.: Refracture, T type: Trabecular type, C type: Cleft type, T: Thoracic vertebra, L: Lumbar vertebra, Fx.: Fracture ${ }^{*}$ Fisher's exact test, ${ }^{\dagger}$ Chi-square test 
for lower extremity pain and lumbodorsal pain due to kyphotic deformity caused by a compression fracture, reported that refractures developed in 11 cases (58\%). The high rate of postoperative refracture results from decreased mobility of the vertebral column due to longsegment fusion and the resulting increase in pressure on adjacent segments. ${ }^{18}$

While vertebroplasty decreases pain at the early stage and allows for rapid patient mobility, it can increase stress on the entire vertebral column, make each segment stiff, and, ultimately, cause a refracture of the cemented vertebra and subsequent fracture of adjacent vertebra. ${ }^{5}$ In fact, Lindsay et al., ${ }^{19}$ who examined refractures that developed after percutaneous vertebroplasty among 312 female patients diagnosed with osteoporosis, reported that $68(21.9 \%)$ refractured a vertebra during the 1-year follow-up after percutaneous vertebroplasty. Syed et al. ${ }^{20}$ also reported that $21.7 \%$ of patients show features of vertebral refracture on MRI 1 year after percutaneous vertebroplasty. The principles of developing a refracture and its relatively high incidence revealed by actual results can cause additional severe pain and medical expenditures for patients who have undergone percutaneous vertebroplasty.

Various studies have presented risk factors for a vertebral refracture after percutaneous vertebroplasty, including steroid use, vertebral regions for cement injection, preoperative gas, and changes in the height of the vertebral body and BMD. ${ }^{2,6,13,14,21,22}$

The volume of gas contained within a vertebral body undergoing a compression fracture makes it possible to estimate the volume of cement to inject during percutaneous vertebroplasty. ${ }^{2}$ Regions containing gas within the vertebral body more frequently undergo a fracture than those without gas. ${ }^{1}$ However, Lin et al. ${ }^{21}$ reported that gas is insignificant as an independent risk factor and found no association between gas and refractures. If gas is discovered within a fractured vertebral body even after vertebroplasty, it is probably because the operator predicted a high possibility for refracture development in the region concerned and injected cement so that no gas would remain. Indeed, few cases have gas remaining after vertebroplasty.

Trout et al. ${ }^{7}$ examined subsequent fractures in terms of vertebral regions during percutaneous vertebroplasty and reported no significant difference by vertebral re- gion. But, the closer the cemented vertebral body was to the fracture, the higher the incidence and the sooner it developed. That study also compared vertebroplasty regions divided by the biomechanics of vertebral mobility such as thoracic, thoraco-lumbar, and lumbar vertebra, in terms of refracture development, but no significant difference was shown. Although vertebral biomechanics, including mobility and weight bearing, are changed by a fracture and repaired through vertebroplasty, it is difficult to predict the risk of refracture by dividing vertebral regions on the basis of normal vertebral biomechanics.

Such factors as cement leakage, cement distribution patterns, and cement injection volume are known in terms of skills. Lin et al ${ }^{12}$ indicated that cement leakage during percutaneous vertebroplasty increases pressure on the lamina terminalis of adjacent vertebra and more frequently cause a subsequent fracture in adjacent vertebra, whereas this study found no significant difference between the vertebral refracture and the cemented vertebral body groups.

The differences in the results of the two studies are due to many variables, including patient BMD, cement injection volume, cement leakage volume, and leakage directions.

Tanigawa et al. ${ }^{15}$ examined cement distribution patterns and cement injection volume and found that a clefttype cement distribution was due to too much injected cement $(4.5 \pm 1.8 \mathrm{ml})$, which led to subsequent fractures in adjacent vertebra $(3.7 \pm 1.6 \mathrm{ml})$ and argued that the larger the cement injection volume, the stiffer the vertebral body concerned; thus, putting greater stress on adjacent vertebral bodies. In this study, we found that a comparison between groups for its incidence was meaningless as more cement $(6.0 \pm 2.1 \mathrm{ml})$ was injected on the average than that in prior studies, and most patients saw an increase in vertebral body stiffness.

Considering the fact that the intensity of kyphosis could be changed by a compression fracture, we not only examined Cobb's angle and the local kyphotic angle but also the sagittal index, which has not been considered in previous studies.

The local kyphotic angle is one of the most frequently used factors reflecting compressive or kyphotic deformity caused by a vertebral fracture and is primarily used to explain the intensity of a fracture. ${ }^{22} \mathrm{Kim}$ et al. ${ }^{23}$ indicated that a kyphotic deformity could develop easily if the local 
kyphotic angle of a fractured vertebra was not corrected well in a case of kyphosis of the entire vertebral column or corrected with posterior fixation for a fracture of a thoraco-lumbar vertebra. Teng et al..$^{22}$ reported that the local kyphotic angle can change to a greater degree than Cobb's angle or height of the vertebral body following percutaneous vertebroplasty. This study found that a compression fracture with a greater local kyphotic angle tended to increase the incidence of vertebral refracture after vertebroplasty $(\mathrm{p}<0.001, \mathrm{p}=0.004)$; refracture of a cemented vertebra occurs more frequently due to the stiffness imbalance within the vertebral body concerned, because cement was intensively injected into the anterior vertebra to correct the local kyphotic angle, which had increased while treating the compression fracture. Additionally, osseous tissues around the anterior vertebral body are restored late and incompletely because of relatively fewer primary periosteal arteries, which are important vertebral body feeding arteries, and are distributed in the anterior vertebral body ${ }^{24}$ Arterial damage more frequently occurs in the anterior region when the vertebral body collapses. ${ }^{25}$ Therefore, the vertebral body around a cemented vertebra may undergo a subsequent fracture because it directly receives the stiffness of the cement without a buffer. The sagittal index can be measured conveniently and is commonly used as an index of kyphotic angle correction for patients with a thoraco-lumbar burst fracture who primarily need operative treatment. ${ }^{16}$ This is because we can not only determine kyphosis of the vertebral column by reflecting the normal sagittal angle but also predict a postoperative kyphotic deformity. ${ }^{16}$ Researchers expected that the sagittal index estimated before percutaneous vertebroplasty would predict progression of a kyphotic deformity and refracture, as a compression fracture also causes kyphotic deformity complications. Our study also indicated significant differences in the sagittal index between the group with vertebral refractures and that without them $(\mathrm{p}<0.001, \mathrm{p}<0.001)$. In terms of measuring the sagittal index, not only a fractured vertebra but also the disk above it is involved in measuring the kyphotic angle. As disks serve as an intervertebral buffer and function to maintain stability of the vertebral column against external forces from diverse directions, a higher preoperative sagittal index reflecting these features can lead to more serious damage to adjacent soft tissues including disks. Therefore, although vertebroplasty restores the deformed angle of a fractured vertebra, deteriorated adjacent soft tissues are present, including disks, which are less competent in maintaining vertebral column stability, which can result in a refracture. Thus, the sagittal index, which has primarily been used for patients with a burst fracture, can also be applied to those who have undergone percutaneous vertebroplasty and be used as a predictive risk factor for vertebral refracture.

We failed to examine the time of menopause because of incomplete gynecological records, which could have affected the rate of osteoporosis. Furthermore, 60 cases is insufficient to draw accurate conclusions. Although two neurosurgeons provided treatment in the same way, it is difficult to completely remove technical differences between them.

\section{CONCLUSION}

We found that the local kyphotic angle and the sagittal index were significant predictive factors among diverse risk factors for vertebral refracture after percutaneous vertebroplasty. Therefore, medical staff should warn patients with a compression fracture and a local kyphotic angle $>15^{\circ}$ and a sagittal index $>12^{\circ}$ before percutaneous vertebroplasty for a high risk of vertebral refracture after percutaneous vertebroplasty. Close follow-up observation is necessary.

\section{REFERENCES}

1. Sohn JM, Kim KW, Ha KY, Ha NK, Kim YH, Kim JH. Risk factors for the progressive osteoporotic spinal fracture. J Korean Spine Surg 2009; 16: 153-159

2. Kim SW, Chung YK. Long term follow-up of osteoporotic vertebral fractures according to the morphologic analysis of fracture pattern. J Korean Soc Spine Surg 2000; 7: 611-617

3. Kallmes DF, Jensen ME. Percutaneous vertebroplasty. Radiology 2003; 229: 27-36

4. Lin WC, Lee YC, Lee CH, Kuo YL, Cheng YF, Lui CC, Cheng TT. Refractures in cemented vertebrae after percutaneous vertebroplasty: a retrospective analysis. Eur Spine J 2008; 17:592-599

5. Ahn Y, Lee JH, Lee HY, Lee SH, Keem SH. Predictive factors for subsequent vertebral fracture after percu- 
taneous vertebroplasty. J Neurosurg Spine 2008; 9: $129-136$

6. Grados F, Depriester C, Cayrolle G, Hardy N, Deramond H, Fardellone P. Long-term observations of vertebral osteoporotic fractures treated by percutaneous vertebroplasty. Rheumatology (Oxford) 2000; 39: $1410-1414$

7. Trout AT, Kallmes DF, Kaufmann TJ. New fractures after vertebroplasty: adjacent fractures occur significantly sooner. AJNR Am J Neuroradiol 2006; 27: 217223

8. Uppin AA, Hirsch JA, Centenera LV, Pfiefer BA, Pazianos AG, Choi IS. Occurrence of new vertebral body fracture after percutaneous vertebroplasty in patients with osteoporosis. Radiology 2003; 226: 119-124

9. Heo DH, Kuh SU. Progressive, repeated lumbar compression fracture at the same level after vertebral kyphoplasty with calcium phosphate cement. Case report. J Neurosurg Spine 2007; 6: 559-562

10. Berlemann U, Ferguson SJ, Nolte LP, Heini PF. Adjacent vertebral failure after vertebroplasty. A biomechanical investigation. J Bone Joint Surg Br 2002; 84: 748-752

11. Kim SH, Kang HS, Choi JA, Ahn JM. Risk factors of new compression fractures in adjacent vertebrae after percutaneous vertebroplasty. Acta Radiol 2004; 45: 440-445

12. Lin EP, Ekholm S, Hiwatashi A, Westesson PL. Vertebroplasty: cement leakage into the disc increases the risk of new fracture of adjacent vertebral body. AJNR 2004; 25: 175-180

13. Voormolen MH, Lohle PN, Juttmann JR, van der Graaf Y, Fransen H, Lampmann LE. The risk of new osteoporotic vertebral compression fractures in the year after percutaneous vertebroplasty. J Vasc Interv Radiol 2006; 17: 71-76

14. Jensen ME, Evans AJ, Mathis JM, Kallmes DF, Cloft HJ, Dion JE. Percutaneous polymethylmethacrylate vertebroplasty in the treatment of osteoporotic vertebral body compression fractures: technical aspects. AJNR Am J Neuroradiol 1997; 18: 1897-1904

15. Tanigawa N, Komemushi A, Kariya S, Kojima H, Shomura Y, Omura N, Sawada S. Relationship between cement distribution pattern and new compression fracture after percutaneous vertebroplasty. AJR 2007; 189: W348-352

16. Farcy JP, Weidenbaum M, Glassman SD. Sagittal index in management of thoracolumbar burst fractures. Spine 1990; 15: 958-965

17. Mathis JM, Barr JD, Belkoff SM, Barr MS, Jensen ME, Deramond H. Percutaneous vertebroplasty: a developing standard of care for vertebral compression fractures. AJNR 2001; 22: 373-381

18. Choi DJ, Ahn DK, Lee S, Park KY, Jun YW, Kim KS. Operative treatment of delayed collapse of osteoporotic vertebral fracture with claudication: transpedicular bone graft and pedicle screw fixation. J Korean Soc Spine Surg 2007; 14: 73-78

19. Lindsay R, Silverman SL, Cooper C, Hanley DA, Barton I, Broy SB, Licata A, Benhamou L, Geusens P, Flowers K, et al. Risk of new vertebral fracture in the year following a fracture. JAMA 2001; 285: 320-323

20. Syed MI, Patel NA, Jan S, Harron MS, Morar K, Shaikh A. New symptomatic vertebral compression fractures within a year following vertebroplasty in osteoporotic women. AJNR 2005; 26: 1601-1604

21. Lin WC, Cheng TT, Lee YC, Wang TN, Cheng YF, Lui $\mathrm{CC}, \mathrm{Yu} \mathrm{CY}$. New vertebral osteoporotic compression fracture after percutaneous vertebroplasty: retrospective analysis of risk factors. J Vasc Interv Radiol 2008; 19: 225-231

22. Teng MM, Wei CJ, Wei LC, Luo CB, Lirng JF, Chang FC, Liu CL, Chang CY. Kyphosis correction and height restoration effects of percutaneous vertebroplasty. AJNR 2003; 24: 1893-1900

23. Kim SK, Kim MH, Lee SC, Min SH, Lee JW. The effect of vertebral wedge angle to the change of kyphotic angle by the posterior instrumentation method in thoracolumbar spine fracture. J Korean Soc Spine Surg 2009; 16: 160-166

24. Son KH, Chung NS, Jeon CH. Measurement of vertebral compression and kyphosis in the thoracolumbar and lumbar fractures. J Korean Soc Spine Surg 2010; 17: $120-126$

25. Ratcliffe JF. Arterial changes in the human vertebral body associated with aging. The ratios of peripheral to central arteries and arterial coiling. Spine 1986; 11: 235-240 